\title{
Bazı İlaç Gruplarının Su Ortamına Olan Etkilerinin Akut Toksisite Testleri ile Değerlendirilmesi
}

\author{
Süheyla TONGUR ${ }^{* 1}$, Sevil YILDIZ², Rıfat YILDIRIM ${ }^{3}$ \\ 1,2Konya Teknik Üniversitesi, Mühendislik ve Doğa Bilimleri Fakültesi, Çevre Mühendisliği Bölümü, Konya \\ ${ }^{1}$ (ORCID:https://orcid.org/0000-0002-8647-6338) \\ ${ }^{2}$ (ORCID:https://orcid.org/0000-0003-2873-9328) \\ 3Isparta Uygulamalı Bilimler Üniversitesi, Sütçüler Prof. Dr. Hasan Gürbüz MYO, Mülkiyet Koruma ve Güvenliği \\ Bölümü, Isparta \\ 3(ORCID:https://orcid.org/0000-0002-4456-9448)
}

(Alınış / Received: 20.06.2018, Kabul / Accepted: 04.03.2019, Online Yayınlanma / Published Online: 11.03.2019)

\author{
Anahtar Kelimeler \\ Analjezik, \\ Beta-blocker, \\ Daphnia magna, \\ Lepidium sativum, \\ Toksisite, \\ EC50
}

\begin{abstract}
Özet: : Bu çalışmanın amacı, reçeteli veya reçetesiz olarak satılabilen ve tüketimleri her geçen gün artan analjezik-antienflamatuvar ve beta-blocker grubu ilaçların laboratuvar ortamında hazırlanan sentetik atıksularının akut toksisitelerinin incelenmesidir. Farklı konsantrasyonlarda hazırlanarak analiz edilecek olan bu ilaçların Lepidium sativum ve Daphnia magna toksisite testleri kullanılarak akut toksisitelerinin değerlendirilmesidir. Ayrıca kullanılan farklı biyolojik test metotlarının duyarlılık yönünden karşılaştırılması ve bu atıksuların bitki ve akuatik yaşam için toksisitesinin belirlenmesidir. Çalışmada, ilaç piyasasında kolaylıkla bulunabilen ve bununla birlikte kullanımları gitgide artan üç farklı ilaç türünün Daphnia magna ve Lepidium sativum toksisite testleri kullanılarak toksisitelerinin belirlenmesi amaçlanmıştır. Test sonuçları incelendiğinde her iki toksisite testi için farklı hassasiyetler gözlenmiştir. Kullanılan yöntemler içerisinde en hassas değerlerin elde edildiği test yönteminin Daphnia magna toksisite test metodu olduğu görülmüştür. Daphnia magna deneyinde ilaç etken maddelerinin 24 saat ve 48 saat sonraki değerleri hesaplanmıştır. Daphnia magna deneyinde sonuçların okunduğu süreler açısından karşılaştırıldığında, 24 saat sonunda okunan değerlere göre 48 saat sonunda alınan değerlerde artış olduğu tespit edilmiştir. Analjeziklerden "Flurbiprofen" etken maddesi için 24 saat ve 48 saat sonraki değerler hesaplandığında Toksik Birim değerinin "çok toksik" olduğu belirlenmiştir. Sonuçlar göz önünde bulundurulduğunda farklı toksisite testlerinin hassasiyetlerinin de farklı olduğu görülmüştür. Bu çalışma toksisite testlerinin ilaç atıksuları üzerinde kullanılabilirliği açısından ve sonraki çalışmalara ışık tutması açısından önemlidir.
\end{abstract}

\section{Assessment of Acute Toxicity of Some Pharmaceuticals Effects in Aquatic Environment by Toxicity Test Methods}

Keywords

Analgesics,

Beta-blocker, Daphnia magna, Lepidium sativum, Toxicity, $\mathrm{EC}_{50}$

\begin{abstract}
Purpose of this study, determination of toxicity effects of synthetic drug solutions (Flurbiprofen, Naproksen and Propranolol) by using toxicity test methods. In this study, Lepidium sativum and Daphnia magna toxicity tests were used as a method to determine potential harms to be caused to microbial ecology in receiver environment by synthetic pharmaceutical solutions were preparing certain concentrations as working samples. When Lepidium sativum and Daphnia magna toxicity tests results were evaluated, different sensitivities were determined for pharmaceutical wastewater samples of different properties. When Lepidium sativum and Daphnia magna toxicity test results were compared, Daphnia magna toxicity test method result was the most sensitive values. Daphnia magna toxicity test method results were compared in terms of times for 24 hours and 48 hours. It was observed that toxic values of pharmaceuticals were increased at 48 hours when compared to the values read at 24 hours. Flurbiprofen showed more toxic than other ingredients (Naproxen and Propranolol) both Lepidium sativum and Daphnia magna. In this study, for plants and aquatic life toxicity of some pharmaceuticals were determined and were compared in terms of sensitivity by using different toxicity test methods. So these studies, in terms of feasibility toxicity test methods are very important on pharmaceutical wastewaters. Also, looking from the viewpoint of next studies of toxicity will be lightning.
\end{abstract}




\section{Giriş}

Dünya nüfusunun gitgide artması ile birlikte nüfusun yoğunlașmasına sebep olmuştur. Ayrıca, hızla gelișen teknoloji yaşamı büyük bir oranda etkisi altına alarak tüketimin artmasına neden olmaktadır. Endüstrileşme ile birlikte yerleşim yerleri hızlı bir şekilde gelişmektedir. Dolayısıyla endüstrilerden, kurumlardan ve konutlardan yoğun bir şekilde kaynaklanan atıkların ortaya çıkması kaçınılabilir bir durum değildir. Yeni teknolojik gelişmelerin yaşam için olumlu tarafları olsa da, ekosistem için olumsuz sayabileceğimiz problemleri meydana getirmektedir. Oluşan atıkların miktarı ve özelliklerinin hem değişmesi hem de artması nedeniyle tehlike oluşturmaktadır. Sonuç olarak, bu durum küresel çapta çevresel kirliliği arttırmaktadır [1].

Fiziki özelliklerine göre atıklar; katı ve sıvı atıklar olmak üzere sınıflandırılabilir. Üretim birimlerinden oluşan atık sular bununla birlikte hastaneler, bakımevleri, çeșitli ișyerleri ve konutların kanalizasyon suları sıvı atıklar; bunun dışındaki atıklar da katı atıklar olarak değerlendirilebilir. Atıkların bir kısmı doğal ortamda hızlı bir şekilde biyodegradasyona uğrayarak çevreye zarar vermeyen bileşenlere dönüşebilirken, ağır metaller ve bazı organik yapıdaki bileşikler ise, uzun yıllar bozunuma uğramadan yapılarını doğada koruyabilmektedirler. $\mathrm{Bu}$ durumla birlikte, insan ve ekosistem üzerinde zarar verici ve olumsuz etkilerini sürdürmelerine yol açmaktadır [2].

İlaç ve kişisel bakım ürünleri sektörü, son 40 yılda hızla gelişme gösteren bir endüstri haline gelmiștir. Fakat ilaçların üretildiği veya tüketildiği alanlarda oluşan ilaç-kaynaklı atıklar, özellikle gelişmekte olan ülkelerde, atık yönetimi konusunda gerektiği önemi kazanamamıştır. İlaçlar, kolay içilebilmeleri ve uzun süre depolanabilmeleri amacı ile mümkün olduğu kadar dayanıklılığı yüksek ve sıvı fazda hareketlilikleri yüksek olacak şekilde üretilmektedirler. Bu özelliklerinden dolayı, ilaç içerisinde bulunan aktif maddeler ve biyotransformasyon ürünleri, ekosistemde birikerek çevreye olumsuz diyebileceğimiz çeşitli etkilere neden olmaktadırlar. Antibiyotikler, antibakteriyel ilaçlar, ağrı kesiciler, betablokerler, kolesterol ilaçları, sitostatik ilaçlar, sentetik steroidler vb. çeşitli araștırmalarla son yıllarda ekosistemde tespit edilen ilaçlardır [3].

İlaçların, ilaç üretim aşamasında kullanılan veya sentezlerde yan ürün olarak elde edilen birtakım kimyasalların atık olarak çevreye geçtiklerinde ortaya çıkabilecek olası zararlı etkilerinin değerlendirilmesi, bu maddelerin yerüstü ve yeraltı su kaynaklarına geçen miktarlarının izlenmesi yakın gelecekte ciddi problemlerin önlenmesi açısından önem verilmesi gereken bir konu halini almıştır [4]. Çünkü kullanılmayan veya raf ömrü dolmuş ilaçlar çöp kutusuna ya da tuvaletlere dökülerek; topikal kullanılan ilaçlar banyo yapılırken yıkama suyuna karışarak; ağızdan alınan ilaçların bir kısmı ise, bağırsaklardan emilmeden; emilen ilaçların kendileri veya metabolitleri de idrar ya da feçes ile kanalizasyon suyuna karışarak ekosistem açısından tehlikeli bir çevresel kontaminasyon kaynağı halini alır.

Toksik madde içeren atıksular, verildikleri alıcı ortama yansıttıkları zararlı etkilerin yanı sıra bu tip atıksuları arıtan biyolojik arıtma tesislerindeki mikroorganizmaları da olumsuz etkileyerek solunum hızlarının değişmesine ve substrat kullanım hızının azalmasına ve dolayısıyla arıtma veriminin düşmesine neden olmaktadırlar [5].

Su kirlenmesi kontrolünde toksisite testleri; su hayatı çevre koşullarının uygunluğunu, atık toksisitesi üzerinde çevresel faktörlerin etkisini, test türü üzerine atığın toksisitesini, atıksu arıtım metotlarının etkisini, su kirliliği kontrolü çalışmalarında gerekli arıtım derecesini ve izin verilebilir atıksu deşarj oranlarının belirlenmesinde ekotoksisite testleri kullanılır. Ülkemizde ise, Su Kirliliği Kontrol Yönetmeliğine göre sadece endüstri kuruluşları için izin verilebilir atık madde deşarj miktarını ve su kalite standartlarına uygunluğunun belirlenmesi amacıyla toksisite testleri uygulanmaktadır [6]. Toksisite testlerinin, çevreye toksik deşarjların verilmesinin kontrol edilmesinde ve denetlenmesinde kimyasal analizler ve biyolojik analizler ile birlikte kullanılmasının gerektiği EPA tarafından önerilmektedir [7].

Atıksu kalitesini ve atıksu deşarjını izlemede zehirliliğin tespit edilmesi amacı ile atıksuyun toksik seviyesinin bilinmesi gerekir. Bazı durumlarda endüstrilerin atıksuları kimyasal parametreler açısından deşarj standartlarını sağlarken, toksisite test sonuçları atıksuyun potansiyel olarak toksik olduğunu göstermektedir. Atıksuyun toksisitesinin bilinmesi arıtma tesislerinin randımanlı bir şekilde işletilebilmesi, alıcı ortamın korunması için oldukça önemlidir. Çevresel risk değerlendirmeleri ve su kalite kontrol uygulamalarında ekotoksisitenin tespit edilebilmesi için biyoanalizlerin yapılması önem taşımaktadır ve gereklidir [8]. Biyolojik izleme sistemleri biyosensör olarak kullanılan organizma üzerindeki ekolojik sonuçların düzeyini gösterir.

Çalışmanın amacı, piyasada en çok bulunan, doktorlar tarafından reçete edilen ya da reçetesiz olarak satılabilen ve tüketimleri her geçen gün artan analjezik - antienflamatuvar ve beta-blocker grubu ilaçların laboratuvar ortamında hazırlanan sentetik atıksularının akut toksisitelerinin deneysel ortamda belirlenmesidir. Çalıșmada, evsel atıksu, endüstriyel atıksu ve yüzeysel sularda en çok karşılaşılan Flurbiprofen, Naproksen ve Propranolol etken maddelerine sahip üç ilaç türünün iki farklı toksisite 
test metodu ile çevreye olan toksik etkilerini belirleme çalışmalarını kapsamaktadır.

\section{Materyal ve Metot}

\subsection{Sentetik atıksu numunesi hazırlama}

Tüm ilaçların stok çözeltisi $2 \mathrm{~g} / \mathrm{L}$ olarak hazırlanmış ve bunlar kullanılarak deney yöntemine göre test çözeltileri hazırlanmıştır. Bazı ilaçlar direkt toz olarak saf su ile hazırlanmış, sudaki çözünürlüğü az olanlar hidroalkolik (< \%1 etanol) çözelti ile hazırlanmıștır.

\subsection{Lepidium sativum toksisite testi}

Lepidium sativum, Crucifare familyasından gelmektedir. Öncelikli olarak başlangıç aşamasında kazık kök gerçekleşmektedir. Kazık kök oluşumu 4 - 6 $\mathrm{cm}$ aralığında uzunluğa ulaştığında yan kök oluşumu gerçekleşmektedir. Kazık kök zamanla kaybolarak saçak kök şeklini almaktadır. Gövde dallanmış otsu bir yapıya sahiptir. Lepidium sativum tohumları genellikle kahverengi ve kahverengimsi kırmızı renklerinde bulunmaktadır. Yaklaşık olarak tohumlar $2 \mathrm{~mm}$ uzunluğunda, $1 \mathrm{~mm}$ genişliğinde ve 0,6 - 1,0 mm aralığında kalınlığa sahiptir. Tohumların minimum çimlenme gücü $\% 80$ civarındadır. Çimlenme toprakta $4^{\circ} \mathrm{C}$ sıcaklıkta başlamaktadır. Lepidium sativum ilıml, nemli iklimlerden hoşlanmaktadır. Yetiştirilme sıcaklığı $10-15 \quad{ }^{\circ} \mathrm{C}$ aralığında olması gelişimi için yeterli olmaktadır. $\mathrm{pH}$ seviyesi 6,0 - 6,5 düzeyinde olmalıdır. Lepidium sativum fazla ıșığı sevmemektedir.

Lepidium sativum toksisite testi Devare ve Bahadır (1994) fitotoksisite üzerine yaptıkları çalışma ile Braunschweig Teknik Üniversitesi Sürdürülebilir Kimya ve Çevre Enstitüsü'nde geliştirilen yönteme göre düzenlenerek yapılmıştır [9,14]. 6 adet kontrol ve 3'er adet \% 0,625, \% 1,25, \% 2,5, \% 5, \% 10 konsantrasyonlarında hazırlanan numuneler için gerçekleştirilmiş, gerekli olduğu durumlarda bu çözelti derişimleri azaltılmış veya yükseltilmiştir. 9 cm'lik cam petri kapları içerisine 2'şer adet $90 \mathrm{~mm}$ çapında Whatman 1 marka filtre kâğıdı yerleştirilerek kontrol petri kaplarına 5'er $\mathrm{mL}$ saf su, numune petrilerine ise hazırlanan farklı seyrelmelerdeki numunelerden 5'er mL konulmuş, filtre kâğıdı altında hiç hava kabarcı̆̆ yerleştirilmiştir. Her bir petri kabının içerisine eşit büyüklükte, zarar görmemiş Lepidium sativum tohumlarından $25^{\prime}$ er adet eşit aralıklarla olacak șekilde yerleștirilmiştir. Petri kaplarının kapakları kapatılarak 72 saat süresince, yaklaşık olarak $25^{\circ} \mathrm{C}$ sıcaklıkta ve karanlı ortamda inkübasyona bırakılmıştır.

Toksisite testinin 72 saatlik inkübasyon süresi sonunda her bir petri kabı içerisinde bulunan Lepidium sativum tohumlarının en iyi gelişim gösteren 20 tanesinin kök uzunlukları ve bitki yükseklikleri ölçülmüştür. Buna göre, test süresi sonunda numunelerin Lepidium sativum tohumlarında gözlemlenen kök uzunluk ve yükseklik ortalama değerleri kontrol petri kaplarında ölçülen ortalama kök uzunluk ve gövde yükseklik değerleri ile kıyaslanarak \% inhibisyonları hesaplanmış buna bağlı olarakta $\mathrm{EC}_{50}$ değerleri ve Toksik Birimleri bulunmuştur.

\subsection{Daphnia magna toksisite testi}

Daphnia magna toksisite testi standart test (OECD, 2004; Test No: 202) prosedürüne göre yapılmıștır $[10,11]$. Standart freshwater çözeltisi kullanılmadan önce 15 dakika süre ile havalandırılmıştır. Daphnia magna yumurtaları (ephippia) sürekli ışık altında (11.000 lux), $20-22^{\circ} \mathrm{C}$ sicaklıkta 72 saat inkübe edilerek larvaların yumurtadan çıkması sağlanmıştır. Yumurtlamaya aşamasına gelen daphnidler, freshwater çözeltisi kullanılarak kaplara aktarılmış ve 24 saat içerisinde yeni çıkmış daphnidler toplanmıştır.

Deney için hazırlanan sentetik numunelerin çözeltisi deney kaplarına konsantrasyon hacimleri giderek artacak şekilde konulmuştur. Farklı konsantrasyonlardaki her bir derişimdeki numune için, test tabağındaki hücrelere 5'er adet Daphnia magna (Straus 1820) (Cladocera, Crustacea) konulmuştur.

Biyodeneylerde, kontrol grubu oluşturularak her kontrol grubuna, deney ortamıla aynı sayıda olacak şekilde 5'er adet Daphnia magna (Straus 1820) (Cladocera, Crustacea) konulmuştur. 24 ve 48 saatlik inkübasyon süresi sonunda her bir deneysel kaptaki hareketsiz ve ölü Daphnia magnalar sayılmıştır. Buna göre, \% inhibisyon oranı kullanılarak grafiksel interpolasyon ile $\mathrm{EC}_{50}$ değerleri hesaplanmıştır.

\section{Bulgular}

Deneyde Flurbiprofen, Naproksen ve Propranolol etken maddelerine sahip üç ilaç türünün farklı seyrelmelerdeki numuneleri için Lepidium sativum ve Daphnia magna toksisite testlerinin hassasiyetleri araştırılmıştır.

Sonuçların kategorize edilmesi için toksisite test sonuçları, toksik birim (TB) olarak ifade edilmiştir. TB sonuçları $\mathrm{TB}=0$ toksik değil, $0<\mathrm{TB}<1$ hafif toksik, $1<\mathrm{TB}<10$ toksik, $11<\mathrm{TB}<100$ çok toksik şeklindeki sinıflandırmaya göre değerlendirilmiştir $[12,13]$.

$$
T B=\left[1 / L(E) C_{50}\right] x 100
$$

\subsection{Lepidium sativum toksisite testi}

Flurbiprofen, Naproksen ve Propranolol etken maddelerine sahip ilaçlar için Lepidium sativum 
toksisite test sonucu hesaplanan $\mathrm{EC}_{50}$ değerleri ve toksik birimleri aşağıda verilmektedir.

Tablo 1. Lepidium sativum $\mathrm{EC}_{50}$ Değerleri (mg/L)

\begin{tabular}{cccc}
\hline E.M.A. & Flurbiprofen & Naproksen & Propranolol \\
\hline Kök & 91,32 & 779.21 & 132.26 \\
\hline Gövde & 82,35 & 485.71 & 242.92 \\
\hline
\end{tabular}

*(E.M.A: Etken madde adı)

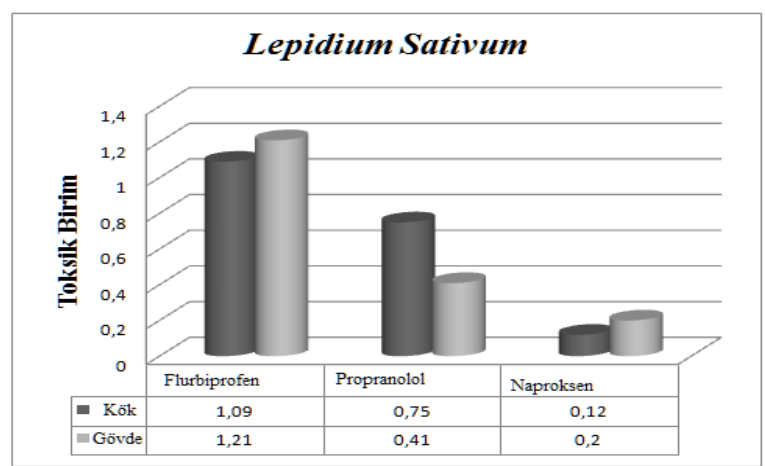

Şekil 1. Lepidium sativum deneyi toksik birimleri

Lepidium sativum toksisite testleri sonucunda toksik birimleri Persoonee ve diğ. (1993) yapmış olduğu sınıflandırmaya göre incelendiğinde kullanılan ilaç numunelerinden Flurbiprofen, Propranolol ve Naproksen etken maddelerinin kökleri için toksik birimleri sirasiyla (TB Flurbiprofen:1,09, TB $_{\text {Propranolol:0,75 }}$ ve $\mathrm{TB}_{\text {Naproksen:0,12) ve gövdeleri için toksik birimleri }}$ ise sirasiyla $\left(\mathrm{TB}_{\text {Flurbiprofen:1,21, }} \mathrm{TB}_{\text {Propranolol:0,41 ve }}\right.$

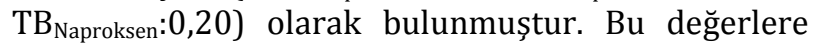
göre Flurbiprofenin "toksik"; Propranolol ve Naproksenin ise "hafif toksik" olduğu tespit edilmiştir.

\subsection{Daphnia magna toksisite testi}

Flurbiprofen, Propranolol ve Naproksen etken maddelerine sahip üç ilaç türü için Daphnia magna toksisite test sonucu 24 saat ve 48 saat sonra okunan $\mathrm{EC}_{50}$ değerleri ve toksik birimleri aşağıda verilmektedir.

Tablo 2. Daphnia magna $\mathrm{EC}_{50}$ Değerleri (mg/L)

\begin{tabular}{cccc}
\hline E. M. A. & Flurbiprofen & Naproksen & Propranolol \\
\hline 24 saat $(\mathrm{mg} / \mathrm{L})$ & 2,21 & 10,39 & 10,16 \\
\hline 48 saat $(\mathrm{mg} / \mathrm{L})$ & 0,0018 & 2,3 & 0,47 \\
\hline *(E.M.A: Etken madde adi) & &
\end{tabular}

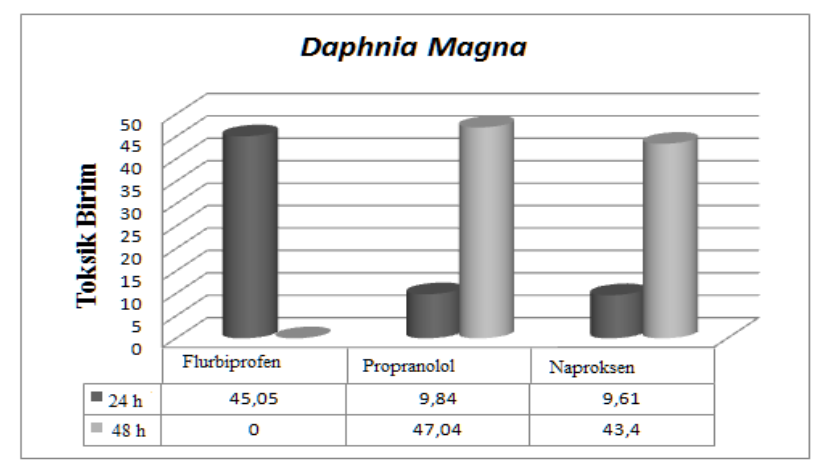

Şekil 2. Daphnia magna deneyi toksik birimleri
Daphnia magna toksisite testleri sonucunda toksik birimleri Persoonee ve diğ. (1993) yapmış olduğu sınıflandırmaya göre incelendiğinde kullanılan ilaç numunelerinden Flurbiprofen, Propranolol ve Naproksen etken maddelerinin 24 saat için toksik birimleri sırasıyla (TB Flurbiprofen:45,05, TB $_{\text {Propranolol:9,84 }}$ ve $\mathrm{TB}_{\text {Naproksen: }} 9,61$ ) ve 48 saat için toksik birimleri ise sırasiyla (TB Flurbiprofen:H.Y, TB Propranolol:47,04 ve

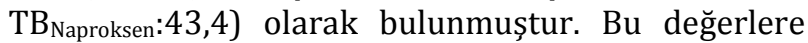
göre 24 saatlik test sonuçları için Flurbiprofenin "çok toksik"; Propranolol ve Naproksenin ise "toksik" olduğu tespit edilmiştir.

\section{Tartışma ve Sonuç}

Yapılan deneyler sonucunda, deneyde kullanılan üç farklı ilaç türünün de toksik etkilerinin bulunduğu görülmüştür. Test sonuçları incelendiğinde her iki toksisite testi, farklı karakterdeki üç ilaç türü için farklı hassasiyetler gösterdiği tespit edilmiştir. Üç farklı ilaç türü için, kullanılan yöntemler içerisinde en hassas değerlerin elde edildiği toksisite test yönteminin Daphnia magna toksisite test metodu olduğu belirlenmiştir.

Her iki toksisite testi için Toksik Birim (Tablo 3) sıralaması; Lepidium sativum toksisite deneyinde, kullanılan ilaç numuneleri için, $\mathrm{TB}_{\text {Flurbiprofen }}>\mathrm{TB}_{\text {Propranol }}>\mathrm{TB}_{\text {Naproksen, Daphnia magna }}$ toksisite deneyinde de, kullanılan ilaç numuneleri için, $\quad \mathrm{TB}_{\text {Flurbiprofen }}>\mathrm{TB}_{\text {Propranol }}>\mathrm{TB}_{\text {Naproksen }}$ olarak bulunmuştur.

Tablo 3. Toksisite testileri sonucu elde edilen toksik birimler

\begin{tabular}{lccc}
\hline TOKSiK BíRiM & Flurbiprofen & Propranolol & Naproksen \\
\hline $\begin{array}{l}\text { Lepidium } \\
\text { sativum (Kök) }\end{array}$ & 1,09 & 0,75 & 0,12 \\
\hline $\begin{array}{l}\text { Lepidium } \\
\text { sativum (Gövde) }\end{array}$ & 1,21 & 0,41 & 0,2 \\
\hline $\begin{array}{l}\text { Daphnia magna } \\
\text { (24 Saat) }\end{array}$ & 45,05 & 9,84 & 9,61 \\
\hline $\begin{array}{l}\text { Daphnia magna } \\
\text { (48 Saat) }\end{array}$ & H.Y & 47,04 & 43,4 \\
\hline Not: H.Y: Hesap Yok & & & \\
\hline
\end{tabular}

Daphnia magna toksisite testi 24 saat ve 48 saat sonraki sonuçlar değerlendirildiğinde, bu test metodunun ilaçların toksisitelerinin belirlenmesinde Lepidium Sativum toksisite testine göre daha fazla hassaslıkla ölçüm yapılabilen bir test metodu olduğu görülmüştür. Deneyde 24 ve 48 saat sonraki toksiklik değerleri karşılaştırılmıştır. Kullanılan ilaçlarda 24 saatlik sonuçlar göz önünde bulundurulduğunda Propranolol ve Naproksen için "toksik", Flurbiprofen için "çok toksik", 48 saatlik sonuçlar için ise Flurbiprofen etken maddesine sahip ilaç için sonuç elde edilememiş ve Propranolol ve Naproksen etken maddelerine sahip ilaç numuneleri için "çok toksik" özellik gösterdiği belirlenmiştir. 
Çalışma sonucunda, toksisite testlerinin duyarlılıkları yönünden karşılaştırıldığında ilaç numunelerinin toksisitelerinin belirlenmesinde kullanılabilecek her iki ekotoksisite testi içerisinde en uygun yöntemin Daphnia magna olduğu, maliyetleri açısından karşılaştırıldığında ise Lepidium sativum toksisite testi olduğu görülmüştür. Aynı zamanda her iki ekotoksisite testi sonucunda Flurbiprofenin, Propranolol ve Naproksenden daha fazla toksik etki gösterdiği tespit edilmiştir.

Yapılan deneyler, ilaçların atıksularda bulunması durumunda çevreye olumsuz etkilerinin olduğunu kanıtlamıștır. Atıksularda, yeraltısularında, içme sularında, çamurda, toprakta ve sedimentte ilaç kalıntıları tespit edilmiştir. Bu sonuçlar ise ilaçların arıtımının ne derece önemli olduğunu kanıtlar niteliktedir.

\section{Kaynakça}

[1] Saygı, Ş., Battal, D., Şahin, N. Ö., 2012, Çevre ve insan sağlığı yönünden ilaç atıklarının önemi, Marmara Pharmaceutical Journal, 16, 82-90.

[2] Ruhoy, I. S., Daughton, C. G., 2008, Beyond the medicine cabinet: An analysis of where and why medications accumulate, Environ Int, 34, 11571169.

[3] Duong, P. A., Pham, N. H., Nguyen, H. T., Huong, T. T., Pham, V. C., Berg, M., Giger, W., Alder, A. C., 2008, Occurence, fate and antibiotics resistance of fluoroquinolore antibacterials in hospital wastewaters in Hanoi, Vietnam, Chemosphere, 72, 968-973.

[4] Larrson, D. G. J., de Pedro, C., Paxeus, N., 2007, Effluent from drug manufactures contains extremely high levels of pharmaceuticals, $J$ Hazard Materials, 148, 751-755.

[5] Meriç, S., Kaplan, D., Selçuk, H., Tünay, O., 2001, Endüstriyel Atıksularda Toksisite İzleme ve Azaltma Yöntemleri, IV. Ulusal Çevre Mühendisliği Kongresi, Ankara, Sayfa 160-167.
[6] SKKY, Su Kirliliği Yönetmeliği Teknik Usuller Tebliği, 1991.

[7] Aydın, M. E., Kara, G., 2006, Organize Sanayi Atıksularının Zehirliliği, S.Ü. Müh. - Mim. Fak. Derg., c.21, s. 3-4.

[8] Aydın, M. A., Yıldız, S., Özcan, S., Kara, G., 2007, Atıksuların toksisitesinin belirlenmesinde farklı biyotest yöntemlerinin uygulanması, 7. Ulusal Çevre Mühendisliği Kongresi, İzmir, 683-700.

[9] Devare, M. And Bahadir, M., 1994, Ecotoxicological assessment of inorganic Waste disposal in salt mines. Part 2 : Phytotoxicity tests, Fresenius Environ, Bull, 3, 119-126.

[10] OECD, Guidelines for testing of chemicals, 2004, Daphnia sp. Acute immobilisation test, 1-12.

[11] Standard Operational Procedure, Daphtoxkit FTM magna, crustacean toxicity screening test for freshwater, 2006, Nazareth, Belgium: MicroBioTests Inc.

[12] Persoonee, G., Goyvaerts, M.P., Janssen, C.R., de Coen W. And Vangheluwe, M., (1993). Costeffective acute hazard moniturin of polluted waters and waste drumps with the aid of Toxkits. Final Report, CEC Contract ACE 89/BE 2/D3, VABRAP, University of Ghent, Belgium, 600 pages.

[13] Persoonee, G., Marsalek, B., Blinova, I., et al,. 2003, A practical and user-friendly toxicity classification system with microbiotests for natural waters and wastewaters. Environ Toxicol., 18(6): 395-402.

[14] Aydin, M., E., Bahadir, M., Kolb, M., et al. Evaluation of sustainable toxicity tests for industrial wastewaters, 2008, TÜBITAK (The Scientific and Technical Research Council Center of Turkey) and JÜLICH (International Bureau of the German Ministry or Education and Research) Project, Project no. 104I136. 